hospital is $£ 52 \mathrm{~s}$. 8d., which is a little more than a 14-day course of ampicillin in the dosage used in this trial.

It would seem, then, that in ampicillin the physician has a useful addition to his armamentarium for the treatment of pneumonia.

\section{Summary}

A controlled trial was carried out to compare the use of ampicillin with a combination of penicillin and streptomycin in the treatment of pneumonia. Seventy-eight patients were allocated to the ampicillin group, in which the régime was oral ampicillin $250 \mathrm{mg}$. six-hourly for 7 or 14 days. Sixtyseven were allocated to the penicillin/streptomycin group, in which the régime required injections of penicillin 1 mega unit b.d. for 7 or 14 days with streptomycin $1 \mathrm{~g}$. b.d. for the first seven days. The treatment groups were comparable, and the results of treatment were similar in the two groups. The only difference of statistical significance was that a larger proportion of cases infected with pneumococci alone became afebrile within one week when treated with ampicillin than when treated with penicillin and streptomycin. Ampicillin appears to be at least as effective as penicillin and streptomycin even in the comparatively small doses used in this trial. There would appear to be an advantage in domiciliary practice in using a drug that can be given by mouth, and if an allowance is made for the cost of giving injections there is little difference in the expense.

Our thanks are due to the following doctors who played a major part in the day-to-day conduct of the trial: Drs. S. I. Ahmed, C. Aitken, A. J. Akhtar, Isobel M. E. Anderson, D. Bell, Kathleen R. M. Brooks, K. A. Buchan, S. Cameron, J. L.
Christie, G. K. Crompton, T. E. Escott, P. Graham, E. Ruth Gray, W. Gray, J. G. Guy, F. F. Hafez, A. C. Harvey, M. D. Haynes, Barbara G. Head, Joyce M. Hendry, C. Hope, Elinor O. S. Hope, Sylvia Jones, A. B. Kay, W. P. U. Kennedy, T. S. Kerr, W. J. H. Leckie, D. O. Lewis, J. Macnamara, T. Middlemass, W. D. Murray, P. L. Pigott, H. Polson, Janet C. Potter, K. D. G. Reid, B. Ritchie, M. Schonell, B. Stack, Sadie D. Walsh, J. B. Wilson, A. Zealley; and to Sisters Black, Boylan, Ferguson, Geekie, Goodwin, Griffiths, McLeod, McSween, Nichol, O'Malley, and Simpson. We are also grateful to Mr. B. A. Burns, Miss Joy E. Chowdray, Mr. J. A. W. Sutherland, Mr. W. J. Webber, and to the many other technicians of the Wellcome Laboratory, City Hospital, and the Central Microbiological Laboratories for technical assistance.

We are particularly grateful to Miss $\mathbf{M}$. C. Drummond, who acted as co-ordinating secretary of the trial. The work forms part of a series of investigations supported by the Wellcome Trust, the Scottish Hospital Endowments Research Trust, the Royal Victoria Hospital Tuberculosis Trust, and the Chest and Heart Association. The ampicillin was generously donated by Beecham Research Laboratories Ltd. through the courtesy of Dr. E. T. Knudsen (Medical Director).

\section{REFERENCES}

Ayliffe, G. A. J., and Pride, N. B. (1962). Brit. med. F., 2, 1641

Bunn, P., O'Brien J., Bentley, D. and Hayman, H. (1962). Antimicrob.

Agents and Chemother., p. 323 .
Elmes, P. C., King, T. K. C., Langland, J. H. M., Mackay, J. A., Wallace, W. F. M., Wade, O. L., and Wilson, T. S. (1965). ' Brit. med. Ұ., 2,904

General Practitioner Clinical Trials (1963). Practitioner, 191, 356.

Grant, I. W. B., Douglas, A. C., and Murray, W. D. (1962). Brit. med. f., 2,482 .

Holloway, W. J., Peters, C. D., and Scott, E. G. (1963). Antimicrob. Agents and Chemother., p. 314.

Howells, C. H., and Tyler, L. E. (1963). Brit. F. clin. Pract., 17, 321.

Trafferd, J. A. P. Maclaren, D. M. Lillicrap, D. A. Barnes, R. D. S., Houston, J. C.., and Knox, R. (1962). Lancet, 1, 987.

\title{
Gastric Aspiration and Lavage in Acute Poisoning
}

\author{
HENRY MATTHEW,* M.B., F.R.C.P.ED. ; T. F. MACKINTOSH,* M.B., D.C.H., M.R.C.P.ED. \\ S. L. TOMPSETT, $\dagger$ D.SC., PH.D., F.R.I.C. ; JEAN C. CAMERON, $\dagger$ A.I.M.L.T.
}

Brit. med. F., 1966, 1, 1333-1337

The management of patients who have ingested poison either accidentally or in attempting suicide presents many problems, not the least of which is whether the stomach should be evacuated. Because of the increasing number of such patients (Ministry of Health, 1962), these problems in management take up much of the time of general practitioners and hospital doctors.

There is no doubt that in certain types of poisoning gastric aspiration and lavage is positively dangerous; this form of therapy therefore has no part to play in the management of poisoning by kerosene and other petroleum distillates (Capel and Gardner, 1960 ; Cachia and Fenech, 1964 ; Baldachin and Melmed, 1964). It should be undertaken with the greatest of care when corrosive poisons have been swallowed, also in alcoholics, in the elderly and very young, and in patients who have undergone gastric surgery. However, the majority of poisoned adults seen in hospital in this country do not fall into these limited groups, and, surprisingly, the advice offered by various authors is contradictory regarding the value of

\footnotetext{
* Poisoning Treatment Centre, Royal Infirmary, Edinburgh.

t University Department of Clinical Chemistry, Royal Infirmary, Edinburgh.
}

gastric aspiration and lavage, particularly in respect of barbiturates, which are by far the commonest drugs taken.

Harstad et al. (1942) demonstrated that even shortly after barbiturate had been ingested little could be recovered by gastric aspiration and lavage. This fact, along with their demonstration that particles of charcoal added to the lavage fluid could later be found in the pulmonary tissues of patients who died, led to the abandonment of gastric lavage by Danish workers (Louw, 1958) and to the use of gastric aspiration alone, without lavage, if it was known that the drug had been taken within one hour previously (Clemmesen and Nilsson, 1961). However, Wright (1955) found that in three out of six cases treated within four hours of ingestion appreciable quantities-that is, over $200 \mathrm{mg}$. of barbiturate-were recovered from the gastric washings. In the six patients treated more than four hours after ingestion no barbiturate was recovered.

Allan (1961), recording his experience with 68 patients, stated that "in most cases of barbiturate overdose, stomach lavage removes only small quantities of ingested barbiturate." $\mathrm{He}$ stressed the hazards associated with the procedure, especially in inexperienced hands, when the patient was semi- 
conscious. He encountered no complications in conscious patients, and stated that endotracheal intubation in deeply unconscious patients "posed no problems." However, he concluded that "routine lavage of the stomach of patients unconscious as a result of barbiturate overdose should be regarded as potentially dangerous in all cases and of no value in most." He did not, however, give any criteria regarding when the procedure might be of value.

Understandably, the practitioner is confused by the advice offered by various authorities. Thus Isbell (1963) advocates gastric lavage only within four hours of ingestion of barbiturate, other authors within eight hours (Graham, 1962 ; Today's Drugs, 1964), and some almost irrespective of the time since ingestion (Deichmann and Gerarde, 1964 ; Davidson, 1964). Clemmesen and Nilsson (1961) and Mark and Papper (1964) employ gastric aspiration alone, without lavage, and then only if the patient is seen within one hour of ingestion of the barbiturate.

In view of the paucity of accurate information on this subject and the divergence of opinion regarding the value of gastric aspiration and lavage in acute poisoning, it was decided to carry out a study on poisoned patients admitted to the Poisoning Treatment Centre in the Edinburgh Royal Infirmary.

\section{Method}

During five months in 1965 gastric aspiration and lavage was carried out on all patients admitted to the Poisoning Treatment Centre who had ingested drugs or poison of any type. There was no case of kerosene poisoning.

In all conscious patients, and in unconscious patients with intact cough and gag reflexes, a large-bore stomach-tube (Jacques, English gauge 30) was passed. If the patient was unconscious, and pharyngeal and laryngeal reflexes were absent, protection of the lungs and patency of the airway was secured by inserting a cuffed endotracheal tube before passing the stomach-tube. After passage of the stomach-tube aspiration of the gastric contents was carried out with the aid of a Senoran evacuator. If no contents could be aspirated $100 \mathrm{ml}$. of water was introduced into the stomach and the fluid aspirated. This initial aspiration specimen was sent for analysis. Gastric lavage was then performed with no more than $300 \mathrm{ml}$. of warm water for each single washout. A total of 2 litres was usually required before the returning fluid was clear, but on occasions when large amounts of food or drug were evident as much as 7 litres was given. An aliquot of the washings was sent for analysis.

Biochemical Methods.-The methods employed were: (1) barbiturates were estimated by ultra-violet spectrophotometry (Unicam spectrophotometry, S.P. 800) (Curry, 1963); (2) aspirin was converted into salicylate by mild alkaline hydrolysis and then determined as such by the Trinder (1954) method; and (3) other substances were estimated by conventional methods, or modifications of them, by means of modern instrumentation such as ultra-violet spectrophotometry.

\section{Results}

From 1 April until 31 August 1965 gastric aspiration and lavage was performed on 259 patients who had ingested poison and were admitted to the Poisoning Treatment Centre. Though a variety of different drugs and other substances had been ingested, $65 \%$ of the patients had taken barbiturate in some form (Table I).

Whenever possible the stomach contents recovered by gastric aspiration and lavage were analysed, but some were not examined, for the following reasons : (1) suitable methods were not available for identification or quantitative determination; (2) when two or more drugs had been taken it was sometimes possible to analyse only the washings for the more important ; and (3) specimens were lost, broken, or inaccurately or wrongly labelled-for this reason analysis was not done in 17 of the barbiturate cases (Table I).

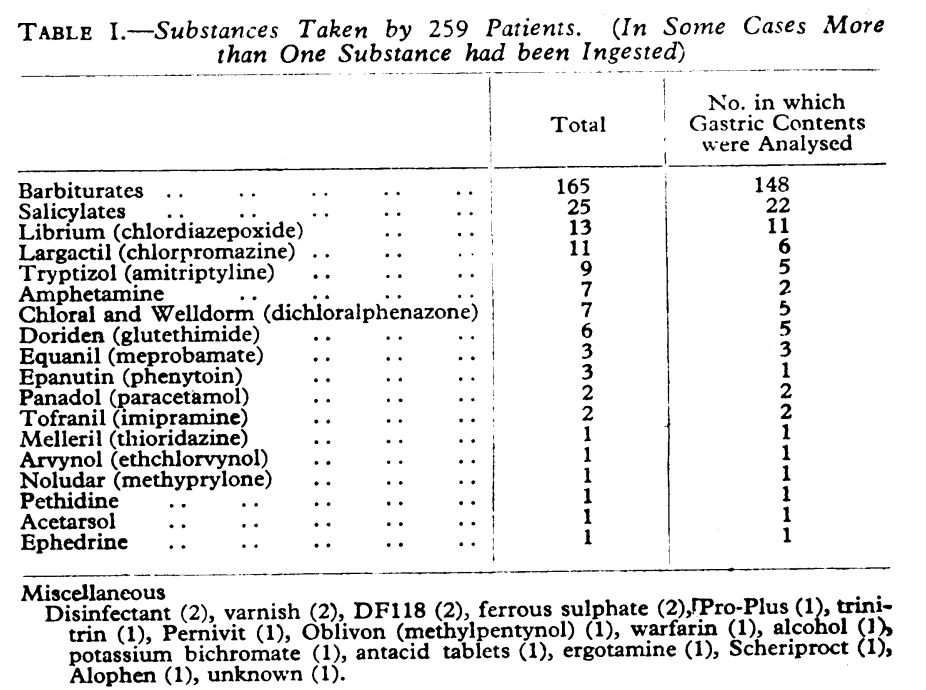

The results obtained in the patients suffering from barbiturate or salicylate poisoning are given in detail below; the less common drugs are mentioned briefly in the Discussion.

\section{Patients Poisoned by Barbiturates}

From the gastric aspirate and washings of 148 (92\%) out of 165 patients suffering from barbiturate poisoning more than $200 \mathrm{mg}$. of barbiturate was recovered in $25(17 \%)$. In 130 patients the time interval between ingestion and wash-out was known with reasonable accuracy, and in Table II and Fig. 1 the total amount of barbiturate recovered from the aspirate and lavage is related to this time interval.

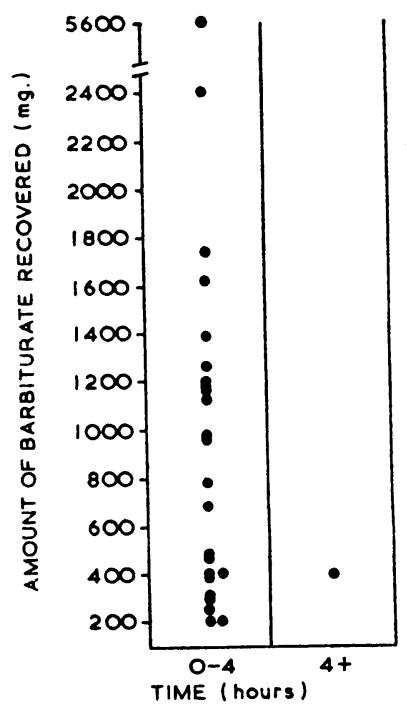

Fig. 1.-Barbiturate recovered (when greater than $200 \mathrm{mg}$.) related to time since ingestion.

TABLB II.-Barbiturate Recovery in Relation to Time

\begin{tabular}{|c|c|c|c|c|c|}
\hline Time (Hours): & $0-4$ & 4-8 & $8-12$ & $12-24$ & $24+$ \\
\hline $\begin{array}{l}\text { No. of patients } \ldots \\
\text { No. in whom more than } 200 \mathrm{mg} . \\
\text { barbiturate was recovered }\end{array}$ & $\begin{array}{l}65 \\
24\end{array}$ & $\begin{array}{r}26 \\
1\end{array}$ & 12 & 23 & $\begin{array}{r}4 \\
-\end{array}$ \\
\hline
\end{tabular}


In 111 patients the number of tablets or capsules taken could be ascertained, and in Fig. 2 the amount of barbiturate recovered in the washings is related to the number of tablets taken. Seldom can one discover with any degree of accuracy the strength of the tablets or capsule incriminated; hence "number" is plotted irrespective of strength.

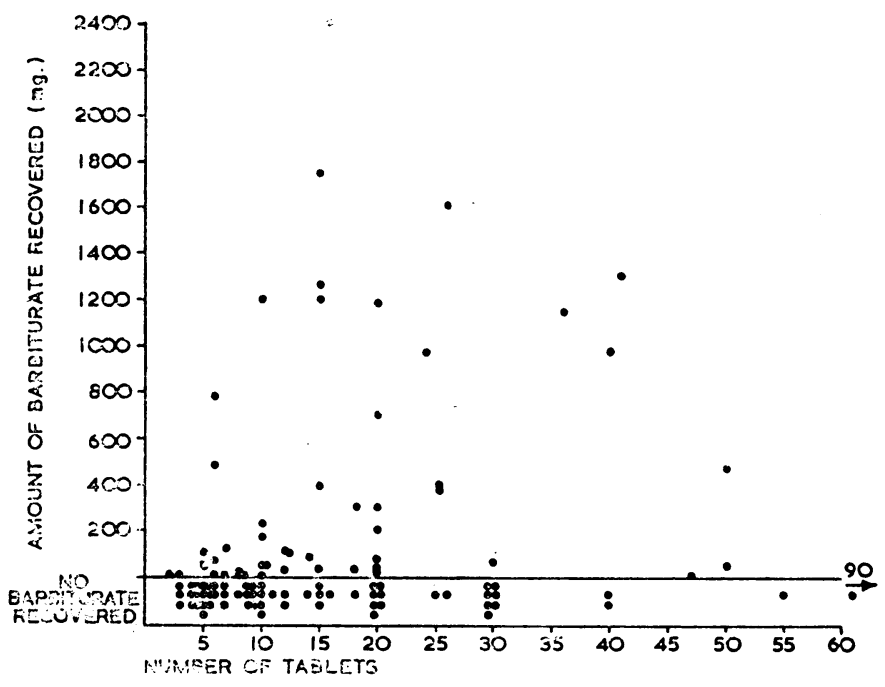

Fig. 2.-Amount of barbiturate recovered related to number of tablets ingested.

In 109 patients both the time interval and the number of tablets or capsules taken were known, and Table III shows the relation between the amount of barbiturate recovered, the number of tablets taken, and the time between ingestion and wash-out.

\begin{tabular}{|c|c|c|c|c|c|c|c|c|}
\hline \multirow{2}{*}{ No. of Tablets: } & \multicolumn{4}{|c|}{ Under 4 Hours } & \multicolumn{4}{|c|}{ Over 4 Hours } \\
\hline & $0-10$ & $11-20$ & $21-50$ & $51+$ & $0-10$ & $11-20$ & $21-50$ & $51+$ \\
\hline \multirow{2}{*}{$\begin{array}{l}\text { No. of patients .. } \\
\text { No. of patients in } \\
\text { whom } 200 \mathrm{mg} \text {. or } \\
\text { more barbiturate } \\
\text { recovered }\end{array}$} & 24 & 24 & 11 & -- & 26 & 11 & 11 & 2 \\
\hline & $\left(\stackrel{4}{4}{ }^{\circ}\right)$ & $(37.5 \%)$ & $(73 \%)$ & - & 一 & $(9 \%)$ & - & - \\
\hline
\end{tabular}

In Fig. 3 the amount recovered is related to the level of consciousness of the patient, the grades of unconsciousness being defined as follows :

Grade 0-Fully conscious.

Grade 1-Drowsy but responds to vocal command.

Grade 2-No response tc vocal command. Maximum response to minimal painful stimuli. Reflexes normal.

Grade 3.-Minimal response to maximal painful stimuli. Tendon reflexes present but often depressed. Pharyngeal and laryngeal reflexes present or absent.

Grade 4-No response to painful stimuli. Tendon, pharyngeal, and laryngeal reflexes absent.

\section{Patients Poisoned by Salicylates}

In salicylate poisoning the patient is almost always conscious, as were all 25 in this study. Table IV shows the amount of salicylate recovered by gastric aspiration and lavage in these patients, together with the time interval since ingestion. The blood salicylate on admission is also shown.

\section{Discussion}

Despite the fact that for many years patients have been admitted to hospital suffering from acute poisoning, the role of gastric aspiration and lavage in treatment is still not clear. Most authorities still advocate wash-out, though the few authors who have investigated this problem have recommended that gastric aspiration and lavage has little place in the management of acute poisoning.

Poisoning, particularly by barbiturate, is becoming more frequent; hence it is essential for criteria to be established on which a decision may be made regarding which patients, if any, should be washed out. By far the most important paper in this field was written by Harstad et al. (1942), and, as their findings have intluenced every author since that time, it is necessary to study their results and analytical methods closely. They investigated 71 cases of barbiturate poisoning. In $40 \mathrm{no}$ barbiturate was recovered on lavage with 10 litres of water. Less than $100 \mathrm{mg}$. of barbiturate was recovered in $86 \%$ of cases, and in only 3\% did recovery amount to more than 500 mg. Those workers suggested that absorption of the drug was in fact increased by this procedure because barbiturate was washed into the small bowel, and they could find no correlation between the amount of barbiturate ingested, the time interval between ingestion and wash-out, and the amount of barbiturate recovered. Furthermore, the finding of charcoal (added to the lavage fluid) in the lungs of patients who died demonstrated the dangers of the procedure. In view of

\begin{tabular}{|c|c|c|c|c|}
\hline $\begin{array}{l}\text { Drug an } \\
\text { No of Tablet: }\end{array}$ & $\begin{array}{l}\text { ind } \\
\text { ets Taken }\end{array}$ & $\begin{array}{l}\text { Time between } \\
\text { Wash-out and } \\
\text { Ingestion } \\
\text { (Hours) }\end{array}$ & $\begin{array}{l}\text { Amount } \\
\text { Salicylate } \\
\text { Recovered } \\
\text { (mg.) }\end{array}$ & $\begin{array}{c}\text { Blood } \\
\text { Salicylate } \\
\text { (mg.) }\end{array}$ \\
\hline 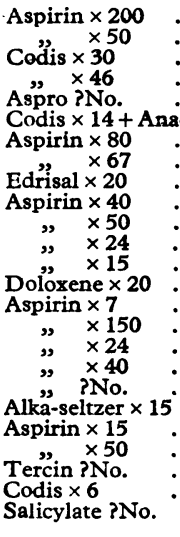 & 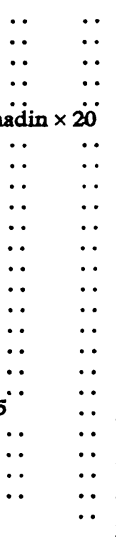 & $\begin{array}{c}9 \\
8 \\
\frac{3}{4} \\
2 \frac{3}{3} \\
? \\
4 \\
5 \frac{1}{5} \\
5 \\
2 \frac{1}{2} \\
1 \frac{1}{4} \\
1 \frac{1}{2} \\
6 \\
2 \frac{3}{4} \\
2 \\
2 \frac{1}{3} \\
13 \\
14 \frac{1}{2} \\
9 \\
24 \\
3 \\
24 \\
12 \\
3 \frac{1}{2} \\
3 \frac{1}{2} \\
?\end{array}$ & $\begin{array}{r}20,340 \\
5,100 \\
4,966 \\
1,753 \\
1,525 \\
1,312 \\
790 \\
575 \\
458 \\
444 \\
408 \\
374 \\
368 \\
242 \\
114 \\
68 \\
54 \\
34 \\
22 \\
\text { Ni1 } \\
\text { " } \\
\text { ", } \\
\text { Not estimated } \\
\text { ״ }\end{array}$ & $\begin{array}{l}67 \\
41 \\
12 \\
19 \\
23 \\
51 \\
25 \\
57 \\
13 \\
26 \\
47 \\
45 \\
21 \\
12 \\
95 \\
27 \\
34 \\
10\end{array}$ \\
\hline
\end{tabular}

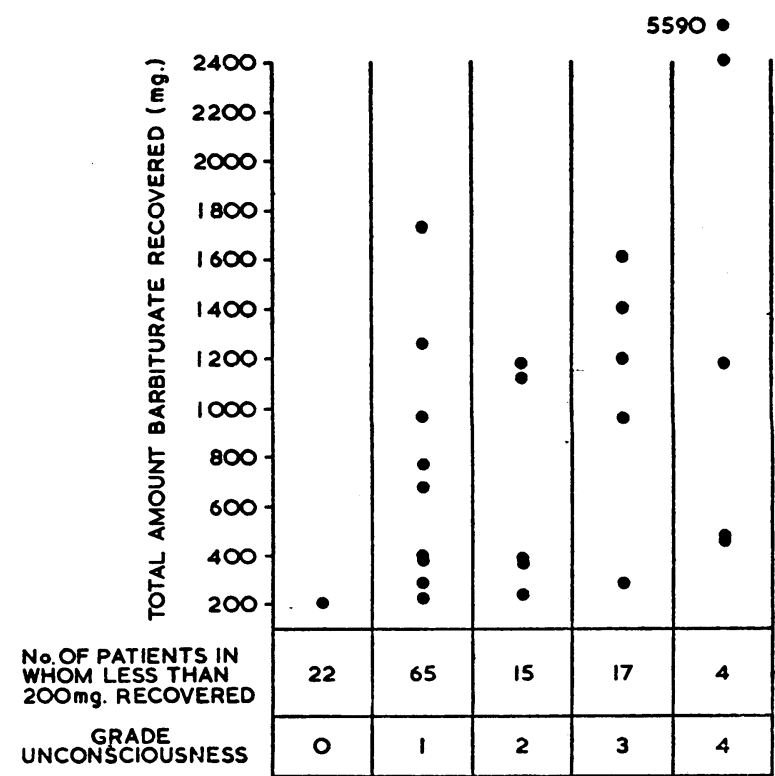
FIG. 3.- Relation between barbiturate recovered and level of 
these dangers and the small quantities of drug recovered, these authors concluded that in no instance could the stomach wash-out have any therapeutic value, and advised abandonment of this procedure in barbiturate poisoning. Their methods of chemical analysis involved solvent-extraction followed by isolation of the substance under investigation by crystallization. Identification was then made by determination of the melting-point. Quantitation was made by weighing the purified substance prepared for the melting-point determination. Such a procedure provides an excellent means for identification purposes, but is of little value for quantitation owing to the extremely large losses involved.

During the 23 years since Harstad's paper was published there have been great technical advances in the methods of analysis as applied to chemical toxicology. New instrumentation-for example, ultra-violet spectrophotometry-has been introduced which allows much more reliable quantitation. Harstad's recommendation, based on what is now known to be inaccurate measurement of the amount of drug recovered, has, however, continued to be quoted as evidence against gastric lavage.

It seemed logical to us that gastric aspiration and lavage would be of some value if the procedure could be undertaken quickly enough after ingestion of the drug, and that there should be little danger if the lungs were protected by a cuffed endotracheal tube in patients whose pharyngeal and laryngeal reflexes were absent.

We think that this assumption is substantiated by our results. We consider that $200 \mathrm{mg}$. or more of barbiturate is a worth-while recovery, and we have shown (Fig. 1) that amounts far in excess of this figure-for example, 5.5 g.can be obtained by stomach wash-out. However, this is achieved only when the patient is washed out within four hours of taking the drug, and this time interval is by far the most important factor in determining the amount of barbiturate recovered. The number of tablets ingested has no direct relation to the quantity of barbiturate recovered (Fig. 2), but when account is also taken of the time since ingestion a correlation is found between the number of tablets taken and the amount recovered (Table III). In patients who were washed out within four hours of taking the drug more than $200 \mathrm{mg}$. of barbiturate was recovered in $73 \%$ of those taking more than 20 tablets, in $37.5 \%$ of those taking 11-20 tablets, but in only $17 \%$ of those ingesting under 10 tablets. Thus within the time limit of four hours the value of the procedure is also, as would be expected, related to the number of tablets ingested.

In patients suffering from barbiturate poisoning who are deeply unconscious bowel sounds are often absent on auscultation of the abdomen (Schreiner, 1958), and in these circumstances absorption stops. Thus the best results from gastric wash-out may be obtained in the deeply unconscious patient about whom little information is available on admission. This is also confirmed by our results. More than $200 \mathrm{mg}$. of barbiturate was recovered in $55 \%$ (5 out of 9) of grade 4, $23 \%$ ( 5 out of 22) of grade 3, 25\% (5 out of 20) of grade 2, and in only $12 \%$ (9 out of 74 ) of grade 1 unconscious patients. In only 1 out of 23 conscious patients was more than $200 \mathrm{mg}$. of barbiturate ever recovered, presumably because these patients had taken so few tablets. In those grade 4 patients who were washed out within four hours of taking the drug more than $200 \mathrm{mg}$. of barbiturate was recovered in five out of six.

We have found that the aspirate always contains a higher concentration of barbiturate than the washings, but the total recovery of barbiturate will be much greater in the washings than in the aspirate, especially if the latter is only of small volume.

Many cases of barbiturate poisoning will not benefit from gastric aspiration and lavage, and the problem is to decide who should receive this treatment. We would suggest that subjects who fulfil the following criteria should be washed out: (1) those who ingested the tablets or capsules within four hours, unless it can definitely be established that fewer than 10 were taken; and (2) if the time of ingestion is not known and the patient is unconscious.

The other hypnotics, tranquillizers, and drugs for use in mental states are not discussed here in detail, but in general we would suggest that the same criteria for stomach wash-out be applied as for barbiturates.

Salicylates do not appear to behave in the same way as barbiturates, in that they remain in the stomach for longer periods (Rushton, 1963; Beveridge et al., 1964) and large amounts of salicylate can be recovered many hours after ingestion (Table IV). One patient in this series ingested 200 5-gr. (325-mg.) aspirin tablets (65 g.) nine hours prior to admission, and $20 \mathrm{~g}$. of salicylate was recovered in the gastric washings. These patients are conscious ; thus gastric aspiration and lavage does not bring the same risk as in the unconscious patient. We would advise gastric aspiration and lavage in all cases of poisoning with salicylates irrespective of the time since ingestion.

Gastric aspiration and lavage does have risks, but we feel that these are often overemphasized-for instance, we have never observed cardiac arrest as a result of the procedure (Lee and Ames, 1965). Perforation of the oesophagus has occurred once in our experience in the last two years : this patient was an elderly chronic alcoholic who was drunk and had been poisoned by barbiturate. However, aspiration of fluid into the lungs with the development of pneumonia can occur. In this series 8 patients (3\%) developed a complication which could possibly have been a result of the gastric aspiration and lavage (Table V). Two of these complications were definitely

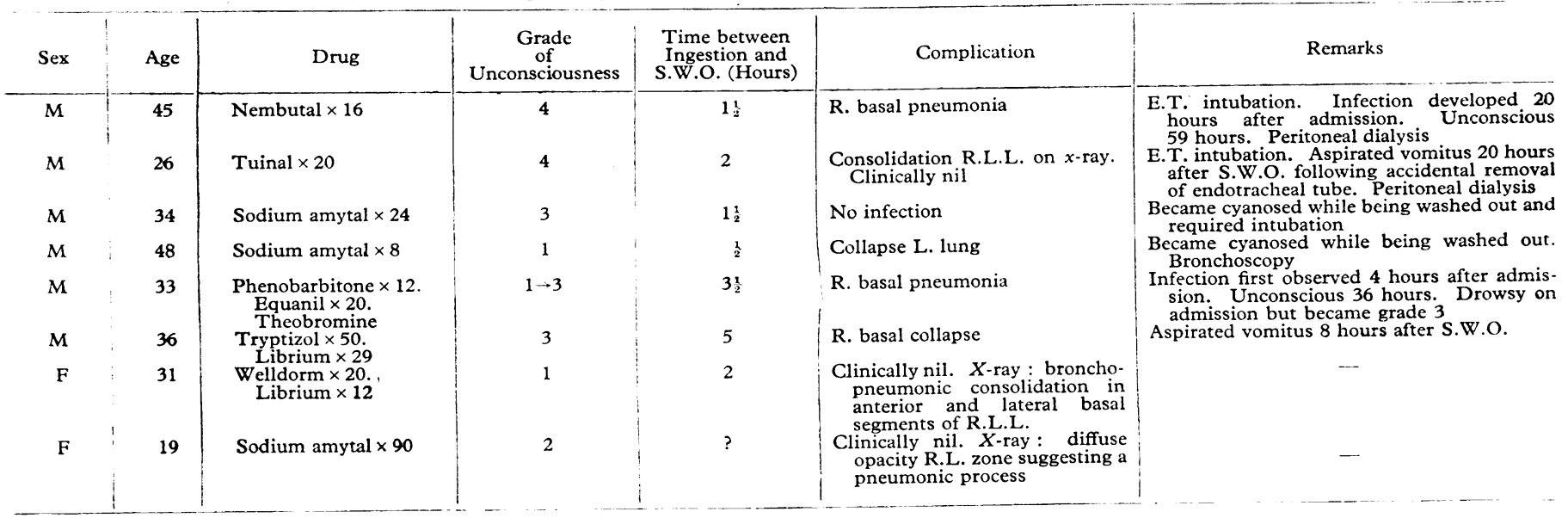


related to the stomach wash-out, but the relation of the remaining six to the procedure is probably fortuitous, as infection may develop prior to admission (Mackintosh and Matthew, 1965). We regard this figure as acceptable in view of the value of gastric aspiration and lavage. Selection of patients with the use of the criteria for wash-out that we suggest, together with efficient protection of the lungs whenever necessary, should reduce the complication rate to a negligible figure. In the deeply unconscious patient a cuffed endotracheal tube should always be inserted prior to passing the stomach-tube. If this cannot be done the procedure should be abandoned.

\section{Summary}

Since advice regarding gastric aspiration and lavage in acute poisoning is confusing and to date has often been based on outmoded methods of quantitative analysis, 259 poisoned patients were studied to assess the value of this procedure, especially with reference to barbiturate and salicylate poisoning.

More than $200 \mathrm{mg}$. of barbiturate was recovered in 24 $(37 \%)$ out of 65 barbiturate cases washed out within four hours of ingestion, but in only 1 out of 65 washed out after four hours.

As much as $20 \mathrm{~g}$. of salicylate was recovered nine hours after ingestion.

Complications of gastric aspiration and lavage were rare.

We would recommend that gastric aspiration and lavage should be performed:(1) in those patients suffering from barbiturate poisoning who ingested the drug within four hours, unless it can be definitely established that fewer than 10 tablets or capsules were taken; (2) if the patient is unconscious and the time of ingestion is not known; and (3) in all cases of salicylate poisoning irrespective of the time of ingestion.

In poisoning by other sedatives, tranquillizers, and antidepressant drugs the advice offered for barbiturate poisoning might probably apply.

This study would not have been possible without the willing help of the house-officer, Dr. R. G. Blomfield, the nursing staff of the Poisoning Treatment Centre, and the Department of Medical Photography, Edinburgh University.

\section{REFERENCES}

Allan, B. C. (1961). Med. F. Aust., 2, 513

Baldachin, B. J., and Melmed, R. N. (1964). Brit. med. f., 2, 28. Beveridge, G. W., Forshall, W., Munro, J. F., Owen, J. A., and Weston, I. A. G. (1964). Lancet, 1, 1406.

Cachia, E. A., and Fenech, F. F. (1964). Arch. Dis. Childh., 39, 502.

Capel, E. H., and Gardner, A. W. (1960). Lancet, 1, 282.

Clemmesen, C., and Nilsson, E. (1961). Clin. Pharmacol. Ther., 2, 220.

Curry, A. S. (1963). Poison Detection in Human Organs. Thomas, Springfield, Illinois.

Davidson, L. S. P. (1964). The Principles and Practice of Medicine, 7th ed., p. 1231. Livingstone, Edinburgh.

Deichmann, W. B., and Gerarde, H. W. (1964). Symptomatology and Therapy of Toxicological Emergencies, p. 3. Academic Press, New York.

Graham, J. D. P. (1962). The Diagnosis and Treatment of Acute Poisoning, p. 90. Oxford Univ. Press, London.

Harstad, E., Møller, K. O., and Simesen, M. H. (1942). Acta med. scand., $112,478$.

Isbell, H. (1963). In Cecil-Loeb Textbook of Medicine, 11th ed., edited by P. B. Beeson and W. McDermott, p. 1740. Saunders, London. Lee, H. A., and Ames, A. C. (1965). Brit. med. F., 1, 1217.

Louw, A. (1958). Dan. med. Bull., 5, 137.

Mackintosh, T. F., and Matthew, H. (1965). Lancet, 1, 1252.

Mark, L. C., and Papper, E. M. (1964). Bulletin-National Clearinghouse for Poison Control Centers, Washington, D.C., Jan. 1964.

Ministry of Health (1962). Emergency Treatment in Hospital of Cases of Acute Poisoning. H.M.S.O., London.

Rushton, D. G. (1963). In Salicylates, edited by A. St. J. Dixon, p. 253. Churchill, London.

Schreiner, G. E. (1958). Arch. intern. Med., 102, 896.

Today's Drugs (1964). Brit. med. F., 2, 928.

Trinder, P. (1954). Biochem. f., 57, 301.

Wright, J. T. (1955). Quart. F. Med., 24, 95.

\title{
Failure of Acute Digitalization to Influence Exercise Tolerance in Angina Pectoris
}

\author{
H. J. SMITH,* M.D., F.R.C.P.(C.) ; G. A. BOUSVAROS,* M.D. ; M. MCGREGOR,* M.D., M.R.C.P., F.R.C.P.(C.)
}

There is good reason to consider the possibility that digitalis glycosides might benefit patients with angina pectoris. Experimental restriction of coronary flow in the dog (Sarnoff et al., 1964) and episodes of angina pectoris in man (Müller and Rørvik, 1958 ; Ross et al., 1962 ; Malmborg, 1965) are often associated with acute elevation of left ventricular end-diastolic pressure or pulmonary capillary wedge pressure. Furthermore, there is good evidence to suggest that depression of ventricular function resulting from ischaemia may be improved by digitalization (Sarnoff et al., 1964).

Previous studies of the value of digitalis compounds in angina pectoris have had conflicting results. Digitalis therapy has been reported to be beneficial (Edens, 1934), valueless (Gold et al., 1938), or detrimental (Freedberg et al., 1941). In a recent investigation it was observed that digitalization prevented anginal pain and acute elevation of pulmonary capillary wedge pressure in 9 out of 17 patients given a standard exercise load (Malmborg, 1965).

We here report a double-blind study designed to detect whether acute digitalization has any therapeutic effect on angina of effort when this is uncomplicated by heart failure.

\section{Material and Method}

Fifteen patients volunteered for study (see Table) and were selected on the grounds that they exhibited angina of effort and were without evidence of valvular heart disease, arrhythmia, congestive failure, or pulmonary disease. Chest radiographs excluded cardiomegaly and pulmonary congestion. Furthermore, at the end of the investigation, when each subject received $2 \mathrm{ml}$. of mercaptomerin, the largest resultant weight loss was $3 \frac{3}{4} \mathrm{lb}$. (1.7 kg.) in 24 hours.

Patients were tested on two separate occasions, one week apart, and on these days they were asked to avoid undue exertion and smoking. No meals were allowed for at least four hours before the tests, which were carried out at the same time of day for each patient. Exercise was performed on a treadmill, the speed of walking and slope having been adjusted on previous occasions so as to precipitate angina of effort within about five minutes. The electrocardiogram was monitored continuously for arrhythmias by means of a bipolar chest lead.

* Joint Cardiorespiratory Service of the Royal Victoria Hospital, McGill University, Montreal, Canada. 